\title{
Right heart failure secondary to traumatic tricuspid flail with severe tricuspid regurgitation
}

\author{
Rodrigo Escalante-Armenta ${ }^{1,2}$, Miguel Tapia-Sansores ${ }^{1,2}$, María Camila Aguirre-Orozco ${ }^{2}$, Luis Javier Castellanos-Vizcaíno ${ }^{1,3}$ and Nilda \\ Espinola-Zavaleta ${ }^{1,4 *}$
}

${ }^{1}$ Nuclear Cardiology Department, National Institute of Cardiology Ignacio chavez,, Mexico City, Mexico

${ }^{2}$ Mexican School of Medicine, La Salle University, Mexico City, Mexico

${ }^{3}$ Health Sciences School, Anahuac University, State of Mexico, Mexico

${ }^{4}$ Echocardiography Department, ABC Medical Center I.A.P., Mexico City, Mexico

\begin{abstract}
Tricuspid flail leaflets are more often due to a post-traumatic lesion, although it can be secondary to infectious endocarditis or a myxomatous degenerated valve.

We present the case of a 46-year-old woman with right heart failure secondary to severe tricuspid regurgitation due to flail of the anterior tricuspid leaflet, probably after surgical repair of the ventricular septal defect.

The tricuspid valve morphology and the severity of tricuspid regurgitation were well characterized by echocardiography.

Despite the fact that the treatment of choice is surgery, the patient remains in functional class II with optimal medical treatment.
\end{abstract}

\section{Introduction}

The term flail tricuspid leaflet refers to a prolapsed leaflet of the tricuspid valve with excursion of the leaflet edge and/or free chords into the right atrium during systole.

Flail tricuspid leaflets are more often due to a post-traumatic lesion, although they can be secondary to infectious endocarditis or a myxomatous degenerated valve. Messika-Zeitoun, et al. studied a group of 60 patients with flail tricuspid leaflet in which $62 \%$ of the cases where traumatic, $50 \%$ were related to blunt chest trauma. Other non-traumatic causes were reported, myxomatous in $12 \%$ of the cases, infective endocarditis in $8 \%$ and congenital in $3 \%$. There is a small percentage of idiopathic cases [1]. In this same study, the tricuspid anterior leaflet was involved in $55 \%$, septal leaflet in $27 \%$, posterior leaflet in $7 \%$ of the patients, both posterior and septal leaflets in $1 \%$, finally there were $10 \%$ of the cases where the flail leaflet was not identifiable [1].

Clinical presentation may vary from asymptomatic to symptomatic patients, and in any case, it is characterized by excess mortality and high morbidity. The most common symptoms experienced are dyspnea, fatigue, right ventricular failure (jugular plethora, hepatomegaly, edema, and ascites), and atrial fibrillation [2-4].

The chronic volume overload leads to adverse right atrial and ventricular hemodynamic consequences $[3,5]$.

Flail leaflets can be opportunely diagnosed using comprehensive two-dimensional, three-dimensional, and Doppler echocardiography. Early surgical intervention is crucial to reduce the high rate of complications following up the diagnosis [6].

Surgical repair of the tricuspid valve is preferred over valve replacement. However, there is risk of significant recurrent regurgitation after repair. Percutaneous interventions may be an alternative for patients with high surgical risk, but further research is needed to decide the optimal management. Surgical outcomes include low operative mortality and marked symptomatic improvement, although there are some reports of refractory atrial fibrillation caused by the delay in the surgical intervention. Reported mortality was $39 \%$ in the 10 year follow-up $[4,7,8]$.

We present the case of a woman in the fifth decade of life with flail of the anterior tricuspid leaflet and severe tricuspid regurgitation, who refused to surgical treatment.

\section{Case presentation}

Female 48-year-old with history of surgical repair of ventricular septal defect at age of 9 . Her main complaint was shortness of breath, dyspnea on mild efforts, fatigue, diffuse abdominal pain, and soft edema on the lower extremities.

The clinical examination revealed shifting abdominal dullness consistent with non-tension ascites, jugular plethora, lower limb edema, and hepatomegaly $4 \mathrm{~cm}$ below the rib margin. Cardiac examination revealed a grade IV/IV holosystolic murmur in the left border of the xiphoidal appendix that increased with inspiration (Rivero Carvallo maneuver) as well as a third heart sound.

${ }^{\star}$ Correspondence to: Nilda Espinola-Zavaleta; $\mathrm{MD}, \mathrm{PhD}$, Juan Badiano $\mathrm{N}^{\circ}$ 1, Colonia Seccion XVI, Tlalpan, P.C. 14080, Mexico City, Mexico, E-mail: niesza2001@hotmail.com

Key words: tricuspid regurgitation, flail leaflet, ventricular septal defect, echocardiography

Received: June 24, 2020; Accepted: July 14, 2020; Published: July 17, 2020 
The laboratory analysis showed an albumin level of $2.5 \mathrm{~g} / \mathrm{dL}$ and BNP of $545 \mathrm{ng} / \mathrm{L}$. The ECG revealed sinus rhythm with heart rate of 61 bpm, QRS angle $140^{\circ}$, right bundle branch block, and intraventricular conduction disorders, (Figure 1). The chest X-ray with cardiomegaly grade III/IV due to dilatation of right cavities.

Transthoracic echocardiogram showed left ventricular systolic dysfunction with left ventricle ejection fraction of $47 \%$, mild dilation of left atrium with indexed volume of $38 \mathrm{ml} / \mathrm{m}^{2}$, dilatation of the right cavities (RV basal diameter- $60 \mathrm{~mm}$, indexed right atrial volume- $139 \mathrm{ml} /$ $\mathrm{m}^{2}$, TAPSE of $17 \mathrm{~mm}$ and an S wave velocity of $9 \mathrm{~cm} / \mathrm{s}$, right ventricular fractional area of $38 \%$, RV thickness of $8 \mathrm{~mm}$, severe tricuspid regurgitation secondary to flail of the anterior leaflet, tricuspid valve with thickening of the leaflets, (Figure 2), residual ventricular septal defect and mild pulmonary hypertension $(47 \mathrm{mmHg})$.

The patient was candidate for a tricuspid valve replacement, but she refused to receive surgical treatment, preferring medical management with Digoxin, Furosemide and Aspirin, with improvement of her symptoms.

\section{Discussion}

Our patient had symptoms consistent with right ventricular failure such as dyspnea, ascites, peripheral edema, and jugular distension,

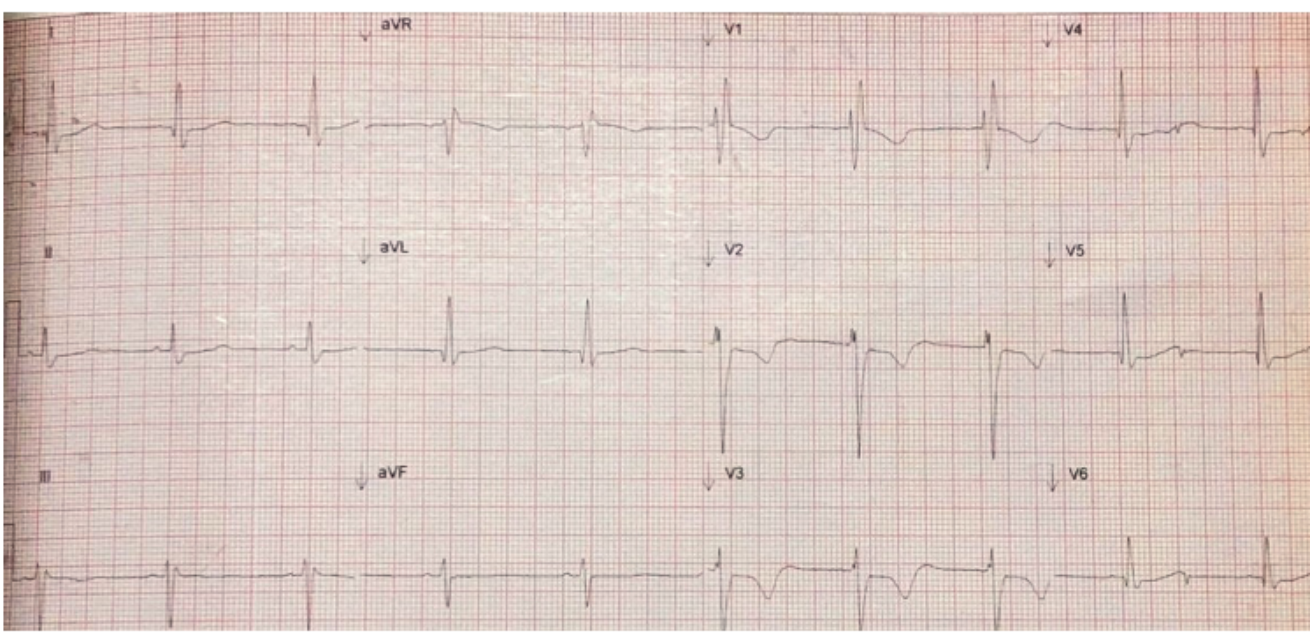

Figure 1. ECG in sinus rhythm with heart rate of $60 \mathrm{bpm}$ and right bundle branch block

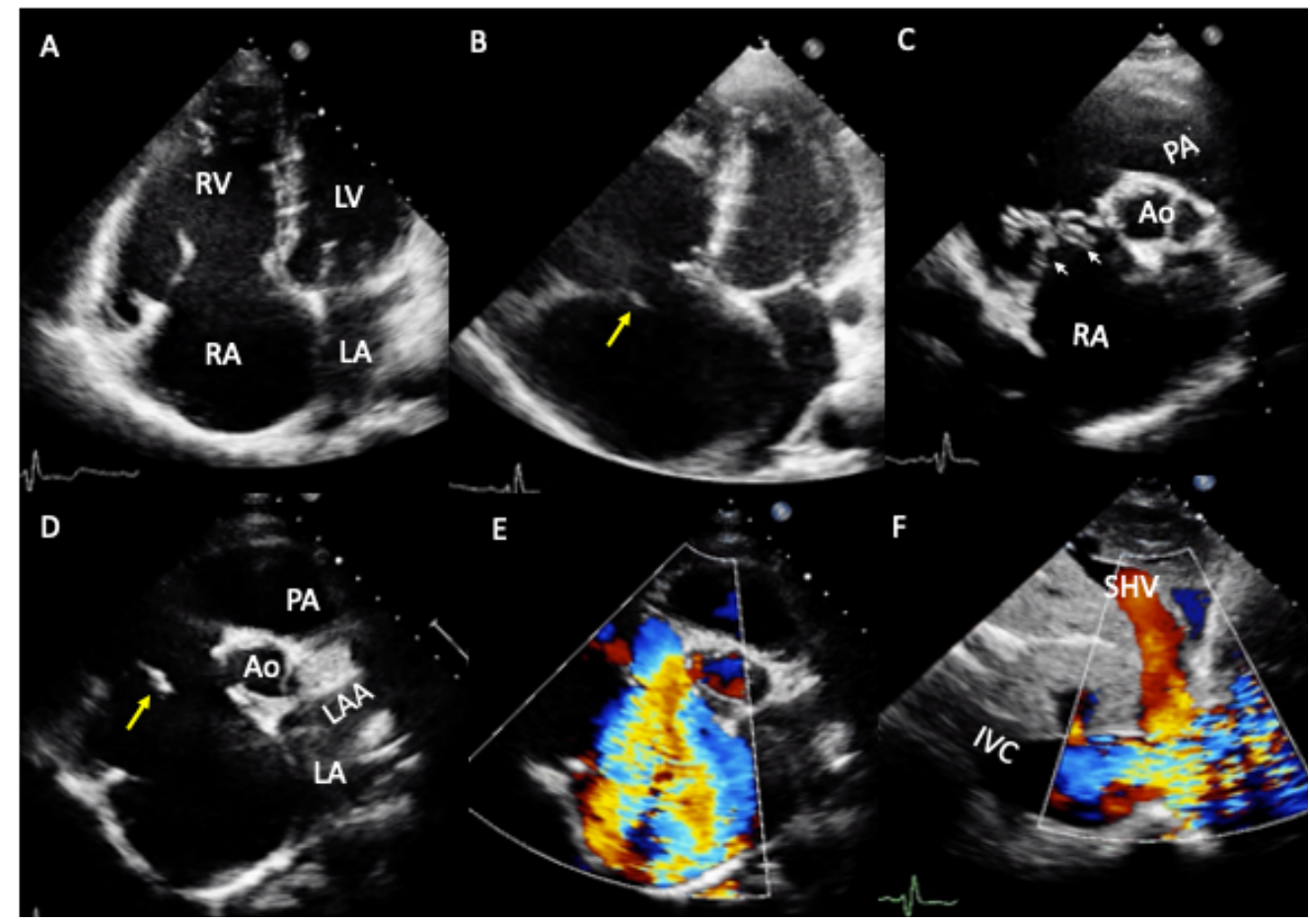

Figure 2. Bidimensional and color flow transthoracic echocardiogram. A- Four chamber view in diastole showing dilation of the right cavities. B-During systole the flail of the anterior tricuspid leaflet is observed (yellow arrow), and the interatrial septum is severely displaced to the left. C- Parasternal short axis view at the level of great arteries with thickening of the septal and anterior tricuspid leaflets (white arrowhead). E- Parasternal short axis view at the level of the great arteries with flail of the anterior tricuspid leaflet (yellow arrow). F- Parasternal short axis view at the level of the great arteries with severe tricuspid regurgitation. G-In the subcostal view, the inferior vena cava (27 mm) and the suprahepatic veins are dilated and the jet of tricuspid regurgitation clearly reaches these veins

Abbrevations: RA-right atrium; RV-Right ventricle; LA-left atrium; LV-left ventricle; Ao-aorta; PA-pulmonary artery; LAA-left atrial appendage; IVC-inferior vena cava; SHV-suprahepatic veins. 
which strongly correlate with the hemodynamic effects of a severe tricuspid regurgitation, probably as a consequence of her previous surgery. We also found a residual ventricular septal defect on the transthoracic echocardiogram, which may have further aggravated the tricuspid regurgitation and further increased her symptoms. The patient was candidate for a tricuspid valve replacement but refused surgical treatment, preferring only medical management, which improvement of her symptoms.

Organic tricuspid regurgitation (TR) is caused by congenital or acquired abnormalities of the tricuspid valve apparatus and represents $8-10 \%$ of all tricuspid regurgitations. Flail tricuspid leaflet can occur with chest trauma, heart surgery or after endomyocardial biopsy or pacemaker implantation due to structural damage [9-11].

Flail of the tricuspid leaflets can arise as a rare complication of surgical repair of ventricular septal defects. The closure of ventricular septal defect performed through a right atriotomy is the most used technique nowadays to correct ventricular septal defects, which can require detachment or incision of the tricuspid valve to obtain a correct exposure of the defect.

Giordano, et al. compared the degree of tricuspid regurgitation on a retrospective analysis of pediatric patients in two groups, one in which incision or detachment of the tricuspid valve was performed and one without incision or detachment, and they found no statistical significant differences on tricuspid regurgitation as a complication at 1 year follow-up ( $47.8 \%$ and $47.6 \%$, respectively) with only $1 \%$ of severe tricuspid regurgitation in the tricuspid valve incision group [12].

Similar information was obtained by Riaz, et al. who did not find postoperative outcome differences on postoperative tricuspid regurgitation or residual ventricular septal defect on the tricuspid valve detachment group when compared to the non-tricuspid detachment group [13]. It suggests that this technique is appropriate and has a low incidence of tricuspid complications, although long term follow-up is required to identify potential chronic complications in patients with tricuspid valve detachment or incision [14].

Currently, echocardiography is the gold standard for evaluating the mechanism and severity of TR. Ideally patients identified with a severe tricuspid regurgitation should be programmed for tricuspid valve repair or replacement. The surgical technique or percutaneous intervention depends mainly on the type and degree of tricuspid regurgitation [15].

\section{Conclusions}

This is a patient who developed symptoms of right heart failure, secondary to a probable traumatic flail of the anterior tricuspid leaflet.

Echocardiography played a very important role in the etiological diagnosis and in the treatment

Despite the fact that the treatment of choice is surgery, the patient remains in functional class II with optimal medical treatment.

\section{Highlights}

- Flail of the tricuspid leaflet refers to a prolapsed leaflet of the tricuspid valve with excursion of the leaflet edge and/or free chords into the right atrium during systole.

- This can occur in chest trauma, cardiac surgery, or after an endomyocardial biopsy or pacemaker implantation.

- Surgical treatment should be considered early in its course to prevent the mortality and morbidity

\section{Financial support}

We report no financial support.

\section{Conflicts of interest}

No conflict of interest between the authors.

\section{Ethical standards}

The authors assert that all procedures contributing to this work comply with the ethical standards of the relevant national guidelines on human experimentation and with the Helsinki Declaration of 1975, as revised in 2008, and has been approved by the institutional committees.

\section{References}

1. https://www.uptodate.com/contents/echocardiographic-evaluation-of-the-tricuspid valve

2. Fender E, Zack C, Nishimura R (2017) Isolated tricuspid regurgitation: outcomes and therapeutic interventions. Heart 104: 798-806.

3. D'Aloia A, Bonadei I, Vizzardi E, Sciatti E, Bugatti S, et al. (2016) Different types of tricuspid flail: Case reports and review of the literature. Hellenic J Cardiol 57: 134137. [Crossref]

4. Messika-Zeitoun D, Thomson H, Bellamy M, Scott C, Tribouilloy C, et al. (2004) Medical and surgical outcome of tricuspid regurgitation caused by flail leaflets. The $J$ Thorac Cardiovasc Surg 128: 296-302. [Crossref]

5. Tarca A, Eckersley L, Kothari D (2017) Flail anterior tricuspid valve leaflet in a neonate: association with maternal antiphospholipid syndrome. Cardiol Young 27: 1637-1640. [Crossref]

6. Lancellotti P, Moura L, Pierard L, Agricola E, Popescu B, et al. (2010) European Association of Echocardiography recommendations for the assessment of valvular regurgitation. Part 2: mitral and tricuspid regurgitation (native valve disease). Eur $J$ Echocardiogr 11: 307-332. [Crossref]

7. Yang X, Wu Q, Xu J, Shen X, Gao S, et al. (2007) Repair of Flail Leaflet of the Tricuspid Valve by a Simple Cusp Remodeling Technique. J Card Surg 22: 333-335.

8. Thors A, Guarneri R, Costantini E, Richmond G (2007) Atrial Septal Rupture, Flai Tricuspid Valve, and Complete Heart Block Due to Nonpenetrating Chest Trauma. Ann Thorac Surg 83: 2207-2210. [Crossref]

9. Kafes H, Ozeke O, Demirkan B, Acar B, Aysenur Ekizler F, et al. (2017) Flail Tricuspid Leaflet During the Percutaneous Closure of Post-Myocardial Infarction Ventricular Septal Defect. CASE (Phila) 1: 207-209. [Crossref]

10. Nishimura RA, Otto CM, Bonow RO, Carabello BA, Erwin JP III, et al. (2014) 2014 AHA/ACC guideline for the management of patients with valvular heart disease: executive summary: a report of the American College of Cardiology/American Heart Association task force on practice guidelines. $J$ Am Coll Cardiol 63: 2438-2488. [Crossref]

11. Prihadi E, Delgado V, Leon M, Enriquez-Sarano M, Topilsky Y, et al. (2019) Morphologic Types of Tricuspid Regurgitation. Characteristics and Prognostic Implications. JACC Cardiovasc Imaging 12: 491-499. [Crossref]

12. Giordano R, Cantinotti M, Di Tommaso L, Comentale G, Tozzi A, et al. (2018) The Fate of the Tricuspid Valve After the Transatrial Closure of the Ventricular Septal Defect. Ann Thorac Surg 106: 1229-1233. [Crossref]

13. Riaz MU, Waqar T, Baig MAR (2017) Comparison of postoperative outcomes with and without tricuspid leaflet detachment in patients undergoing ventricular septal defect repairs. J Postgrad Med Inst 31: 247-250.

14. Said S, Burkhart H, Dearani J (2012) Surgical Management of Congenital (NonEbstein) Tricuspid Valve Regurgitation. Semin Thorac Cardiovasc Surg Pediatr Card Surg Annu 15: 46-60. [Crossref]

15. Arsalan M, Walther T, Smith R, Grayburn P (2015) Tricuspid regurgitation diagnosis and treatment. Eur Heart J 38: 634-638. [Crossref]

Copyright: (C2020 Escalante-Armenta R. This is an open-access article distributed under the terms of the Creative Commons Attribution License, which permits unrestricted use, distribution, and reproduction in any medium, provided the original author and source are credited. 